\title{
HUBUNGAN GAYA KEPEMIMPINAN TERHADAP PRODUKTIVITAS KERJA KARYAWAN BAGIAN LIQUID PT ITRASAL YANG DIMEDIASI OLEH MOTIVASI KERJA
}

\author{
Endang Rachmawati \\ Fakultas Farmasi Universitas Wahid Hasyim \\ Jl. Menoreh Tengah X/22 Sampangan Semarang 50236 \\ endangrachmawati11@yahoo.com
}

\section{INTISARI}

Penelitian ini bertujuan untuk mengidentifikasi hubungan Gaya Kepemimpinan terhadap Produktivitas Karyawan PT. ITRASAL yang dimediasi oleh Motivasi Kerja. Penelitian ini menggunakan rancangan penelitian metode asosiatif dengan jenis penelitian survey yang akan mengungkapkan hubungan dua variabel, yaitu Gaya Kepemimpinan sebagai variabel bebas dan Produktivitas sebagai variabel terikat. Data primer berasal dari kuesioner yang disebarkan kepada karyawan bagian Liquid Departemen Produksi PT ITRASAL, dan hasil diskusi dengan karyawan bagian tersebut. Selanjutnya data yang diperoleh dianalisis menggunakan metode korelasi dan regresi linear. Dari penelitian ini diperoleh hasil bahwa nilai $r$ untuk variabel Gaya Kepemimpinan terhadap Produktivitas adalah 0,557 dan nilai $\mathrm{t}$ adalah 8.951. Nilai $\mathrm{r}$ untuk variabel Gaya Kepemimpinan terhadap Motivasi adalah 0,278 dan nilai $t$ adalah 5,022. Terdapat hubungan positif antara Gaya Kepemimpinan terhadap Produktivitas dan Gaya Kepemimpinan berpengaruh positif terhadap Motivasi. Nilai $\mathrm{r}$ untuk variabel Motivasi terhadap Produktivitas adalah 0,377 dan nilai $\mathrm{t}$ adalah 6,251. Terdapat hubungan positif antara Motivasi terhadap Produktivitas.

Kata kunci : Gaya kepemimpinan, Motivasi kerja, Produktivitas karyawan

\begin{abstract}
This study aims to identify the relationship of leadership style to employee productivity PT. ITRASAL is mediated by work motivation. This research uses the research design of associative method with the type of survey research that will reveal the relationship of two variables, namely Leadership Style as independent variable and productivity as dependent variable. Primary data comes from a questionnaire distributed to employees of the Liquid Department of Production Department of PT ITRASAL, and the results of discussions with employees of that section. Further data obtained were analyzed using correlation and linear regression method. From this research, the result that $r$ value for leadership style variable to productivity is 0,557 and $t$ value is 8,951 . The $r$ value for the leadership style variable for motivation is 0.278 and the $t$ value is 5.022 . There is a positive relationship between leadership style on productivity and leadership style have a positive effect on motivation. The $\mathrm{r}$ value for the Motivation variable on productivity is 0.377 and the $t$ value is 6.251 . There is a positive relationship between motivation to productivity.
\end{abstract}

Keywords: Leadership style, Motivation work, Employee productivity

Corresponding author:

Endang Rachmawati

Fakultas Farmasi Universitas Wahid Hasyim

Jalan Menoreh Tengah X-22, Sampangan, Semarang

endangrachmawati11@yahoo.com 


\section{PENDAHULUAN}

Perekonomian domestik yang cukup kuat dan semakin membaik diperkirakan akan meningkatkan permintaan berbagai produk consumer goods, termasuk permintaan terhadap produk farmasi. Besarnya populasi penduduk, semakin tingginya pola hidup dan kesadaran masyarakat akan kesehatan serta dukungan program pemerintah di bidang kesehatan juga menjadi basis yang kuat bagi perkembangan industri farmasi Indonesia dewasa ini. Hal ini mengakibatkan persaingan bisnis dalam industri farmasi semakin ketat dimana diversifikasi produk semakin banyak dilakukan pemain besar (Anonim, 2010).

Bagian di dalam Departemen Produksi yang paling mengandalkan gaya kepemimpinan sebagai salah satu cara untuk mengatur keberlangsungan proses produksi adalah bagian liquid. Kapasitas mesin produksi yang tidak sama, disertai dengan tahapan proses produksi yang panjang dan beresiko tinggi terhadap kesalahan, menyebabkan operator bagian liquid tersebut dituntut untuk mengerti dengan baik apa yang menjadi tugasnya dan bagaimana melaksanakannya. Namun demikian, di sisi lain, inisiatif bekerja operator bagian liquid masih rendah, dan pengetahuan yang dimiliki kurang memadai. Sehingga, efektifitas proses produksi didasarkan pada bagaimana Supervisor dan Koordinator Produksi Liquid dalam memimpin, mengelola, dan mengarahkan SDM yang dipimpinnya.

Berdasarkan kondisi tersebut, maka peneliti berkeinginan melakukan penelitian yang berkaitan dengan hubungan Gaya Kepemimpinan terhadap Produktivitas Departemen Produksi PT ITRASAL yang dimediasi oleh Motivasi Kerja. Peneliti ingin mengetahui apakah Gaya Kepemimpinan yang dominan diterapkan di bagian liquid. Selain itu peneliti juga ingin mengetahui apakah Motivasi Kerja memediasi pengaruh Gaya Kepemimpinan terhadap Produktivitas Karyawan PT ITRASAL.

\section{METODOLOGI PENELITIAN}

Penelitian ini menggunakan rancangan penelitian metode asosiatif dengan jenis penelitian survey yang akan mengungkapkan hubungan tiga variabel, yaitu Gaya Kepemimpinan sebagai variabel bebas, Motivasi Kerja Karyawan sebagai variabel perantara, dan kinerja atau Produktivitas Bagian Liquid Departemen Produksi PT. ITRASAL sebagai variabel terikat.

Data yang dikumpulkan meliputi data primer. Data primer berasal kuesioner yang disebarkan kepada karyawan Bagian Liquid Departemen Produksi PT. ITRASAL, dan hasil diskusi dengan karyawan bagian tersebut. Hasil diskusi dan observasi digunakan untuk mendukung penelitian yang dilakukan.

\section{Bahan Penelitian}

Responden dalam penelitian ini adalah seluruh Operator Bagian Liquid Departemen Produksi PT ITRASAL selama bulan Juli sampai Desember 2017 yang berjumlah 64 orang. Responden dalam penelitian ini adalah yang memenuhi kriteria inklusi, yaitu umur antara 19-55 tahun, masa kerja minimal 6 bulan, bersedia menjadi responden, mampu membaca dan menulis. Kriteria eksklusi adalah masa kerja kurang dari 6 bulan, berumur kurang dari 19 tahun atau lebih dari 55 tahun, serta tidak bersedia menjadi responden.

\section{Alat Penelitian}

\section{Jalan Penelitian}

Alat penelitian yang digunakan yaitu kuesioner, dan lembar diskusi operator.

\section{Pengambilan Data}

Pengambilan data dilakukan di bagian Liquid Departemen Produksi PT ITRASAL.

JIFFK Vol. 15, No. 1, JUNI 2018, Hal. 51 - 56 


\section{Analisis Data}

Data yang diperoleh dari kuesioner dan data produktivitas dianalisis dengan menggunakan teknik korelasi product moment untuk mengetahui arah dan kekuatan hubungan antar variable, sedangkan teknik korelasi regresi linear digunakan untuk mengetahui pengaruh variabel bebas terhadap variabel terkendali.

\section{HASIL PENELITIAN}

\section{Hasil Uji Validitas dan Reliabilitas Alat Ukur}

Dari hasil pengujian validitas alat ukur instrument Gaya Kepemimpinan Supervisor Produksi yang terdiri dari 32 butir pertanyaan, semua pertanyaan dinyatakan valid dengan nilai reliabilitasnya sebesar 0.911 dengan kata lain kehandalan pertanyaan tersebut sebesar $91,1 \%$ atau bisa dikatakan reliable. Untuk instrument Motivasi Kerja Karyawan yang terdiri dari 20 butir pernyatann ternyata semua butir pernyataan dinyatakan valid, dengan nilai reliabilitasnya sebesar 0.941 dengan kata lain kehandalan pernyataan tersebut sebesar $94,1 \%$ atau bisa dikatakan reliable.

Sedangkan untuk instrument Produktivitas yang terdiri dari 23 butir pernyataan dinyatakan valid, dengan nilai reliabilitasnya sebesar 0.784 dengan kata lain kehandalan pernyataan tersebut sebesar $78,4 \%$ atau bias dikatakan relible

Tabel I. Hubungan Tingkat Pendidikan dan Masa Kerja Operator terhadap Gaya Kepemimpinan.

\begin{tabular}{ccc}
\hline \multicolumn{3}{c}{ Gaya Kepemimpinan Direktif } \\
\hline Tingkat Pendidikan & Masa Kerja & Jumlah \\
\hline D3 & L & 1 \\
SMU & B & 1 \\
SMU & S & 5 \\
SMU & L & 8 \\
SMP & B & 3 \\
SMP & S & 2 \\
SMP & L & 15 \\
SD & L & 3 \\
\hline
\end{tabular}

\begin{tabular}{ccc}
\hline \multicolumn{3}{c}{ Gaya Kepemimpinan Konsultatif } \\
\hline Tingkat Pendidikan & Masa Kerja & Jumlah \\
\hline SMU & B & 2 \\
SMU & S & 7 \\
SMU & L & 9 \\
SMP & B & 3 \\
SMP & S & 2 \\
SMP & L & 18 \\
SD & L & 4 \\
\hline
\end{tabular}

Gaya Kepemimpinan Partisipasif

\begin{tabular}{ccc}
\hline Tingkat Pendidikan & Masa Kerja & Jumlah \\
\hline SMU & B & 1 \\
SMU & S & 6 \\
SMU & L & 9 \\
SMP & B & 3 \\
SMP & S & 2 \\
SMP & L & 17 \\
SD & L & 6 \\
\hline
\end{tabular}

Gaya Kepemimpinan Delegatif 


\begin{tabular}{ccc}
\hline Tingkat Pendidikan & Masa Kerja & Jumlah \\
\hline SMU & B & 2 \\
SMU & S & 6 \\
SMU & L & 9 \\
SMP & B & 2 \\
SMP & S & 2 \\
SMP & L & 16 \\
SD & L & 5 \\
\hline
\end{tabular}

$$
\begin{aligned}
& \text { Keterangan: } \\
& \text { Lama masa kerja operator: } \\
& \mathrm{B}=<1 \text { tahun } \\
& \mathrm{S}=1-5 \text { tahun } \\
& \mathrm{L}=>5 \text { tahun }
\end{aligned}
$$

Hubungan tingkat pendidikan dan masa kerja operator terhadap gaya kepemimpinan ( Tabel I ) menunjukkan hasil bahwa responden memiliki tingkat pendidikan D3 1 responden, pendidikan SMU sebanyak 20 responden, pendidikan SMP 32 responden, dan Pendidikan SD 11 responden. Dari data diatas dapat diketahui bahwa karyawan bagian Liquid cenderung menginginkan supervisor dengan Gaya Kepemimpinan secara hirarki adalah dengan Gaya Kepemimpinan Konsultatif sebanyak 18 responden, Partisipatif 17 responden, dan Delegatif 16 responden. Ketiga gaya ini dinyatakan oleh responden dengan tingkat pendidikan SMP dengan masa kerja lebih dari 5 tahun.

\section{Hasil Analisa Korelasi Gaya Kepemimpinan, Motivasi, dan Produktivitas}

a. Analisis korelasi Gaya Kepemimpinan supervisor bagian Liquid Departemen Produksi terhadap Produktivitas Operator Bagian Liquid Departemen Produksi

\section{Tabel II. Korelasi Gaya Kepemimpinan Supervisor Bagian Liquid Departemen Produksi terhadap Produktivitas Operator Bagian Liquid}

\begin{tabular}{ccccc}
\hline Variabel Bebas & $\begin{array}{c}\text { Variabel } \\
\text { Tergantung }\end{array}$ & $\begin{array}{c}\text { Nilai } \\
\mathbf{r}\end{array}$ & $\begin{array}{c}\text { Nilai t } \\
\text { hitung }\end{array}$ & $\begin{array}{c}\text { Nilai } \\
\mathbf{t} \\
\text { tabel }\end{array}$ \\
\hline $\begin{array}{c}\text { Gaya } \\
\text { Kepemimpinan }\end{array}$ & Produktivitas & 0,557 & 8,951 & 1,999 \\
\hline
\end{tabular}

Korelasi Gaya Kepemimpinan supervisor bagian Liquid Departemen Produksi terhadap Produktivitas Operator Bagian Liquid ( Tabel II ), menunjukkan hasil bahwa terdapat hubungan antara Gaya Kepemimpinan supervisor produksi dengan Produktivitas Kerja operator bagian liquid departemen produksi yang dipersepsikan oleh operator. Hasil nilai t hitung lebih besar dari nilai $t$ tabel maka gaya kepemimpinan mempengaruhi produktivitas operator.

b. Analisis korelasi Gaya Kepemimpinan supervisor bagian Liquid Departemen Produksi terhadap Motivasi operator bagian Liquid Departemen Produksi. 
Tabel III. Korelasi Gaya Kepemimpinan Supervisor Bagian Liquid Departemen Produksi terhadap Motivasi Operator Bagian Liquid

\begin{tabular}{ccccc}
\hline Variabel Bebas & $\begin{array}{c}\text { Variabel } \\
\text { Tergantung }\end{array}$ & Nilai r & $\begin{array}{c}\text { Nilai t } \\
\text { hitung }\end{array}$ & $\begin{array}{c}\text { Nilai t } \\
\text { tabel }\end{array}$ \\
\hline Gaya Kepemimpinan & Motivasi & 0,278 & 5,022 & 1,999 \\
\hline
\end{tabular}

Korelasi gaya kepemimpinan supervisor bagian Liquid Departemen Produksi terhadap Motivasi Operator Bagian Liquid ( Tabel III ), menunjukkan hasil bahwa terdapat hubungan antara gaya kepemimpinan supervisor produksi dengan Motivasi operator bagian liquid departemen produksi yang dipersepsikan oleh operator. Melihat hasil analisa tersebut nilai $\mathrm{r}$ yang diperoleh, dapat dikatakan bahwa gaya kepemimpinan supervisor produksi berpengaruh secara positif terhadap motivasi operator liquid. Artinya gaya kepemimpinan supervisor bagian liquid departemen produksi mampu meningkatkan motivasi operator bagian liquid.

c. Analisis korelasi motivasi operator bagian Liquid departemen produksi terhadap Produktivitas operator bagian Liquid departemen produksi

Tabel IV. Korelasi Motivasi Operator Bagian Liquid Departemen Produksi terhadap Produktivitas Operator Bagian Liquid

\begin{tabular}{ccccc}
\hline Variabel Bebas & $\begin{array}{c}\text { Variabel } \\
\text { Tergantung }\end{array}$ & Nilai r & $\begin{array}{c}\text { Nilai t } \\
\text { hitung }\end{array}$ & $\begin{array}{c}\text { Nilai t } \\
\text { tabel }\end{array}$ \\
\hline Motivasi & Produktivitas & 0,377 & 6,251 & 1,999 \\
\hline
\end{tabular}

Korelasi Motivasi operator bagian Liquid Departemen Produksi terhadap Produktivitas Operator Bagian Liquid ( Tabel IV ), menunjukkan hasil bahwa terdapat hubungan antara Motivasi Operator bagian liquid dengan produktivitas operator bagian liquid departemen produksi yang dipersepsikan oleh operator. Melihat hasil analisa tersebut nilai $r$ yang diperoleh, dapat dikatakan bahwa motivasi operator bagian liquid berpengaruh secara positif terhadap produktivitas operator bagian liquid. Artinya adalah motivasi kerja operator bagian liquid departemen produksi mampu meningkatkan produktivitas operator bagian liquid.

d. Analisis korelasi antara variabel gaya kepemimpinan, variabel motivasi kerja, dan Variabel Produktivitas.

Melihat hasil korelasi yang diuraikan sebelumnya, dapat dikatakan bahwa gaya kepemimpinan supervisor bagian liquid departemen produksi berpengaruh secara positif terhadap motivasi operator bagian liquid. Artinya adalah gaya kepemimpinan supervisor bagian liquid mampu meningkatkan motivasi operator bagian liquid. Kemudian motivasi operator Bagian liquid berpengaruh positif terhadap produktivitas operator bagian liquid, artinya adalah motivasi operator bagian liquid mampu meningkatkan produktivitas operator bagian liquid. Sedangkan gaya kepemimpinan supervisor produksi memiliki hubungan positif terhadap produktivitas operator bagian liquid. Artinya adalah gaya kepemimpinan yang digunakan oleh supervisor produksi dapat meningkatkan produktivitas operator bagian liquid secara langsung.

Hasil - hasil korelasi yang diperoleh dapat disimpulkan bahwa di bagian liquid operator bagian produksi PT ITRASAL, supervisor bagian liquid departemen produksi bisa menggunakan gaya kepemimpinan untuk mempengaruhi produktivitas operator, selain itu supervisor produksi juga 
bisa menggunakan gaya kepemimpinan untuk meningkatkan motivasi operator dalam bekerja. Dengan meningkatkan motivasi operator dalam bekerja maka produktivitas operator akan meningkat. Hal tersebut sesuai dengan hasil penelitian Rajiv Mehta dkk (2003), Suraningsig (2010).

\section{KESIMPULAN}

1. Gaya kepemimpinan yang paling dominan diterapkan di bagian liquid departemen produksi adalah gaya kepemimpinan konsultatif dan partisipasif.

2. Terdapat pengaruh signifikan antara gaya kepemimpinan supervisor produksi, produktivitas operator bagian liquid dan motivasi kerja operator bagian liquid. Terdapat pengaruh langsung antara gaya kepemimpinan supervisor produksi terhadap produktivitas operator bagian liquid dan motivasi kerja operator bagian liquid. Adanya pengaruh antara gaya kepemimpinan supervisor bagian liquid departemen produksi terhadap produktivitas operator bagian liquid diperantarai oleh motivasi kerja operator bagian liquid departemen produksi

\section{UCAPAN TERIMA KASIH}

Rasa terima kasih peneliti ucapkan kepada segenap pihak terutama pihak manajemen dan rekan - rekan tempat peneliti bekerja di PT ITRASAL serta keluarga yang telah mendukung dan memberikan waktu sehingga penelitian ini dapat berjalan hingga selesai.

\section{DAFTAR PUSTAKA}

Anonim, 2010, Meninjau Industri Farmasi Indonesia, http://bataviase.co.id/node/508665 (diakses tanggal 9 Juli 2011).

Rajiv, M., Alan, J. D., dan Rolph, E. A., 2003, Leadership Style, Motivation and Performance in International Marketing Channels, European Journal of Marketing, 2003; 37, 1/2; ABI/INFORM Global, (Online), http://www.google.co.id/url?sa=t\&rct=j\&q=journal+leadership+style+motivation+and+p erformance+in+international+marketing \&source $=$ web\&cd $=3 \& c a d=r j a \& v e d=0 C D Y Q F j A$ C\&url=http\%3A\%2F\%2Fwww.academicjournals.org\%2FAJBM\%2FPDF\%2Fpdf2011\% 2F16Sept\%2FChipunza\%2520\%2520et\%2520al.pdf\&ei=IUFRUMTuEly0rAelo4CQCg \&usg=AFQjCNGnRF9EIvllfJldioOJj1QgRsDTQw.

Suraningsih, E., 2010, Pengaruh Kompetensi Umum dan Kepemimpinan Terhadap Kinerja Manajer pada Badan Usaha Milik Negara Perkebunan, Disertasi, Dr. Magister Manajemen Agrobisnis, Universitas Gadjah Mada, Yogyakarta, 191-195. 